\title{
A quantal step function in duration discrimination
}

\author{
ALFRED B. KRISTOFFERSON \\ McMaster University, Hamilton, Ontario L8S 4K1, Canada
}

\begin{abstract}
The difference threshold for duration, for the case of empty time intervals bounded by brief auditory pulses, is an increasing function of base duration. For base durations between 100 and $1,480 \mathrm{msec}$, Weber's law describes the function quite well and a Weber ratio of .05 is obtained. These results in the present paper conform closely to results that have been reported by others. However, it is further shown that the function changes as the amount of practice is increased at each specific base duration: steps unfold from the linear function, and these steps are clearly evident after 17 consecutive sessions at each base duration. Expressing threshold in terms of the apparent magnitude of the "time quantum," it is found that $q$ is about $13 \mathrm{msec}$ when base duration is $100 \mathrm{msec}$ and that it jumps to 25 at 200 , to 50 at 400 , and to 100 at 800 . Between the abrupt risers in this step function, the treads are not quite flat, perhaps because the amount of practice was insufficient. It is concluded that the time quantum can be doubled and halved, at least within the doubles set 13,25 , 50 , and $100 \mathrm{msec}$. It is not restricted to the single value of $50 \mathrm{msec}$ as initially proposed (Kristofferson, 1967).
\end{abstract}

The time quantum cannot be a constant of about $50 \mathrm{msec}$ as originally proposed (Kristofferson, 1967) and also be the sole limiting factor which determines the difference threshold for duration (Allan \& Kristofferson, 1974; Allan, Kristofferson, \& Wiens, 1971; Kristofferson, 1977). The reason is obvious: the threshold for duration is not a single value, even in the limit. Instead, the threshold for duration is usually, but not always, an increasing function of base duration (see Allan, 1979, and Allan \& Kristofferson, 1974, for reviews of the literature on this relationship). How the quantum changes in magnitude as a function of base duration is the question examined in this paper.

The threshold for duration appears to increase monotonically and continuously when the duration stimuli are empty time intervals bounded by brief auditory signals (Getty, 1975). Getty measured discriminability at 15 base durations ranging from 50 to 3,200 msec. He concluded that "the underlying function is continuous and strictly monotone increasing" and that a modified Weber's law is valid for base durations less than $2,000 \mathrm{msec}$. In the experiment reported here, duration stimuli like Getty's are used and base durations are within his Weber's law range and cover most of that range.

The variability of an internally timed time interval that is initiated by a brief auditory signal is reduced

This research was supported by Grant $A 7919$ from the National Research Council of Canada. A preliminary report of these results was presented to the Lake Ontario Vision Establishment meeting in Niagara Falls, Ontario, on $M$ arch 9, 1973. by practice, and prolonged practice is necessary to reach a stationary level (Kristofferson, 1976). A large component of the practice effect is not general, but rather is specific to the particular interval being timed so that the practice gain may be lost if the subject is required to time an interval different from the practiced interval. In addition, under certain conditions, the mechanism of duration discrimination requires such an internally timed interval (Kristofferson, 1977). Since Getty used a single base duration within a session but changed base duration randomly from session to session, it is possible that his subjects were effectively unpracticed in spite of their many sessions. In the present experiment, prolonged practice was conducted at each base duration before moving on to the next base duration.

\section{METHOD}

\section{Apparatus and Procedure}

A stimulus set consisted of four duration stimuli $\left(S_{1}, S_{2}, S_{3}\right.$, $S_{4}$ ) defined as the time between onsets of two brief auditory pulses. The shortest duration was that of $S_{1}$, which is denoted $D_{1} ; D_{2}, D_{3}$, and $D_{4}$ were progressively longer. A single stimulus was presented on a trial, and the subject was instructed to decide whether it was "short" $\left(S_{1}\right.$ or $\left.S_{2}\right)$ or "long" $\left(S_{3}\right.$ or $\left.S_{4}\right)$ and to signal his decision by pressing one of two buttons. $D_{2}$ and $D_{3}$ were set so that they were imperfectly discriminable; the midpoint between them defined the base duration for the stimulus set. $D_{1}$ and $D_{4}$ were set at values which should place them below $\left(D_{1}\right)$ and above $\left(D_{4}\right)$ the psychophysical range. That range extends from one quantum $(q)$ below the subject's criterion $\left(D_{c}\right)$ to one $q$ above it, $D_{c}$ being defined as that $D$ yielding $50 \%$ "long" responses. The value of $D_{c}$ is usually very close to the midpoint between $D_{2}$ and $D_{3}$. $S_{1}$ and $S_{4}$ should be classified without error according to the realtime criterion theory (Kristofferson, 1977), and they are included 
in each stimulus set for the purpose of monitoring the subject. The logic of this single-stimulus "many-to-few" method and the way in which a value of q can be calculated from $P(L)$, the probability of a long response, has been discussed in detail elsewhere (Allan \& Kristofferson, 1974; Kristofferson, 1977).

Thirteen stimulus sets, with midpoints (base durations) ranging from 100 to $1,480 \mathrm{msec}$, were used. Twenty consecutive daily sessions were conducted with each set before the next set was begun. Thus, the experiment consisted of 260 sessions, with the order of stimulus-set as given in Table 1 .

For the first 15 sessions of a 20 -session series for a given midpoint, the stimulus set was as described above. For Sessions 16-20, $S_{1}$ and $S_{4}$ were replaced by $S_{5}$ and $S_{6}$, respectively. $D_{5}$ was set at a duration between $D_{2}$ and $D_{c}$, and $D_{6}$ was set at a value between $\mathrm{D}_{\mathrm{c}}$ and $\mathrm{D}_{3}$.

One subject, the author, served in this experiment. He is an experienced subject, and extensive related data for him have been published previously (Kristof ferson, 1976, 1977).

An experimental session required about $40 \mathrm{~min}$ and consisted of three blocks of 100 trials each with a brief rest between blocks. The three blocks were identical except for the order of stimulus presentation, which was random. The four stimuli were presented approximately an equal number of times per session.

The stimulus patterns, response buttons, and computer program were the same as described earlier (Kristofferson, 1976, 1977), except that responses were not speeded and response latencies were not recorded, because this experiment was done prior to the development of the technique of speeded responding.

Each trial began with an auditory warning signal, followed $1,000 \mathrm{msec}$ later by the duration stimulus. The duration stimulus consisted of two identical successive auditory pulses, $P_{1}$ and $P_{2}$, and the stimulus duration was the time between their onsets. The auditory pulses each had a duration of $10 \mathrm{msec}$. They were $2,000-\mathrm{Hz}$ sinusoids gated at zero-crossing with a rise-decay time of $2.5 \mathrm{msec}$ and an intensity of $68 \mathrm{~dB}$ re .0002 dynes $/ \mathrm{cm}^{2}$ when on continuously.' A visual feedback signal occurred following the response period to tell the subject whether the duration had been "long" or "short."

\section{Data Analysis}

The data for each of the 260 sessions consist of the proportion of long responses, $\mathrm{P}(\mathrm{L})$, for each of the four duration stimuli. Theoretical parameter values were estimated from the four response probabilities for each session separately.

For Sessions 1-15, $P(L)$ for $S_{1}$ and $S_{4}$, the monitoring stimuli, were used to estimate $K$, the probability of processing the stimulus, and $\beta$, the probability of $R(L)$ given a failure to process, as follows:

$$
K=P\left[R(L) / S_{4}\right]-P\left[R(L) / S_{1}\right]
$$

and

$$
\beta=\frac{P\left[R(L) / S_{1}\right]}{1-K} .
$$

The obtained response probabilities for $S_{2}$ and $S_{3}$ were then adjusted for processing errors using $K$ and $\beta$ to yield a corrected response probability, $\alpha$ :

$$
\alpha=\frac{\mathrm{P}(\mathrm{L})-\beta(1-\mathrm{K})}{\mathrm{K}} .
$$

For Sessions 16-20, the mean value of $K$ and $\beta$ for Sessions 11-15 were used in Equation 3 to adjust all four response proportions. The theoretical basis for this procedure has been discussed by Allan and Kristofferson (1974).

The adjusted response probabilities, $a$, were then used to calculate the quantum size $(q)$ and the expected value of the criterion $\left(D_{c}\right)$ for each session. One such pair of values was obtained from $\alpha_{2}$ and $\alpha_{3}$ for every session and a second pair from $\alpha_{5}$ and $\alpha_{6}$ for Ses- sions 16-20. These calculations are also described by Allan and Kristofferson (1974) and contain the assumptions of the real-time criterion theory (Kristofferson, 1977). Briefly, if $\alpha_{\mathrm{i}}$ is less than .5, then the stimulus falls below $D_{c}$ by $A$ units of $q$. If $\alpha_{i}$ is greater than .5, the stimulus is $B$ q-units above $D_{c}$ and

$$
A=1-\sqrt{2 \alpha}
$$

while

$$
\mathrm{B}=1-\sqrt{2(1-\alpha)}
$$

The distance between the two stimuli in $q$ units is $d_{q}$ and

$$
\mathrm{d}_{\mathrm{q}}=|\mathbf{A}|+|\mathbf{B}| \text {. }
$$

The parameter $d_{q}$ is like $d^{\prime}$ of signal detection theory except that $\mathbf{A}$ and $\mathbf{B}$ are triangular rather than normal deviates.

The quantum size is

$$
\mathrm{q}=\frac{\Delta \mathrm{D}}{\mathrm{d}_{\mathrm{q}}},
$$

in which $\triangle \mathrm{D}$ is the difference between the two stimulus durations. The mean value of the criterion is

$$
D_{c}=D_{2}+|A| \times q,
$$

in which $D_{2}$ is the duration of the stimulus yielding the $a<.5$.

This theory assumes that the psychophysical function, $P(L)$ vs. $\Delta \mathrm{D}$, is the cumulative form of a discriminal dispersion that is an isosceles triangle with a base of $2 \mathrm{q}$. The triangle is the convolution of two independent quantal units, each uniformly distributed over a range of one $q$. The psychophysical function is sigmoidal, but fully bounded (Kristofferson \& Allan, 1973), and resembles a normal ogive. Since the variance of the triangular distribution is $q^{2} / 6$, the standard deviation of the psychophysical function is directly proportional to $\mathrm{q}$ :

$$
\mathrm{SD}=.408 \mathrm{q} .
$$

The main results will be presented in terms of quantum size as a function of base duration. This function can be transformed without changing its shape into SD vs. base duration by applying Equation 6.

\section{RESULTS AND DISCUSSION}

The form of the functional relationship between the threshold for duration and base duration (BD) depends upon specific practice. After what must be called a moderate amount of practice, 17 sessions at each base duration, the function is as shown in Figure $1 .^{2}$ The rate of increase in $\mathrm{q}$ as base duration increases is slow, except in certain narrow regions where it is very fast. The line segments in Figure 1 are drawn so as to emphasize these steps. The rapid steps, or risers, occur at approximately 200,400 , and $800 \mathrm{msec}$, and the values of $\mathrm{q}$ at base durations of $100,200,400$, and 800 are very close to $13,25,50$, and $100 \mathrm{msec}$. However, the treads of the steps are not flat; they have an appreciable slope and they all have nearly the same slope.

If $\mathrm{q}$ were simply directly proportional to $\mathrm{BD}$, such as is shown by the dashed line in Figure 1, a "dou- 


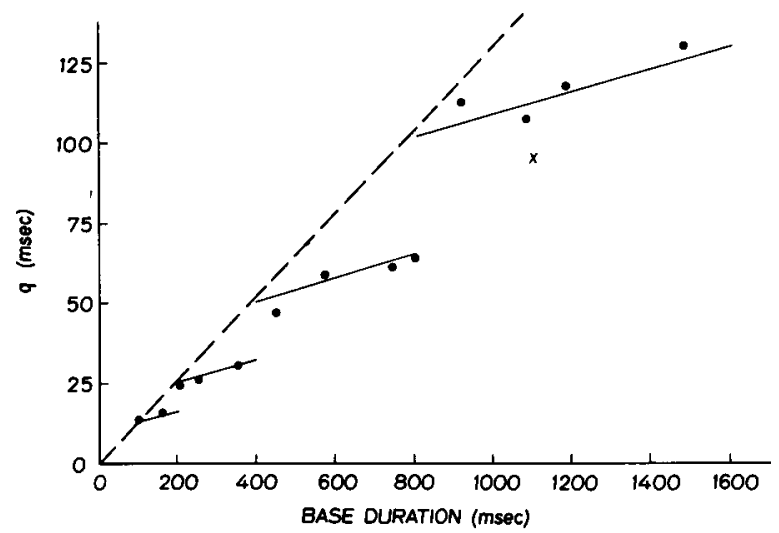

Figure 1. Quantum size (87\% threshold $\Delta D$ ) as a function of base duration for the data of Sessions 18-20 at each base duration. The line segments are derived from the least squares line of Figure 2, which was doubled and halved as explained in the text. The dashed line is from Figure 3 and represents performance on Sessions 1-5. The steps unfold from the line with increasing practice. The $X$ represents quantum size for a base duration of 1,100 msec for the same subject, A.K., as reported in Kristofferson (1977), after even more extensive practice.

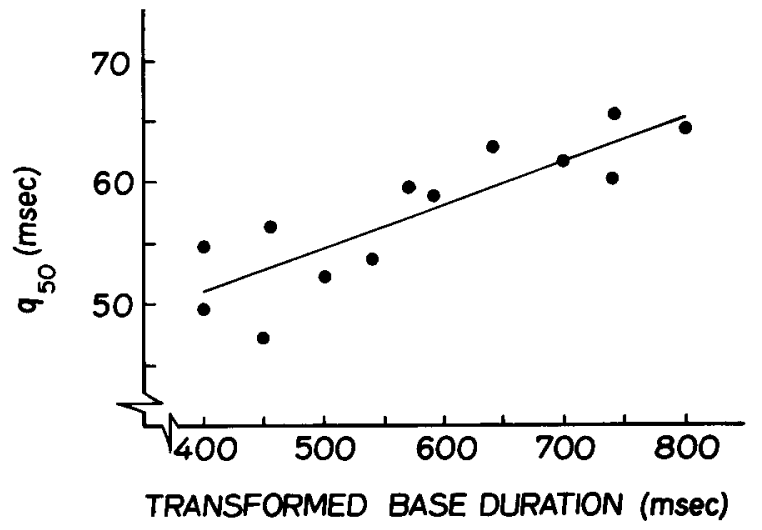

Figure 2. Quantum size for each base duration in Figure 1 transformed into the $q_{s 0}$ range by appropriate doubling or halving of both coordinates. The slope of the least squares line is $\mathbf{. 0 3 5 6}$, and its intercept at the $400-\mathrm{msec}$ base duration is $51.1 \mathrm{msec}$. bling" rule would describe the relationship: Doubling or halving base duration a given number of times doubles or halves $q$ the same number of times. Figure 1 shows that while $\mathrm{q}$ is clearly not a zero-intercept, linear function of $\mathrm{BD}$, the doubling rule still describes the step function. If the data points in the range of base durations between 800 and 1,600 (the $\mathrm{q}_{100}$ range) are transformed by dividing both of their coordinates by two, they map upon the $q_{s o}$ line segment. Similarly, doubling the $q_{25}$ points and doubling twice the $q_{13}$ points maps them into the $q_{50}$ range.

This doubling transformation was performed to produce the set of points displayed in Figure 2. The least squares line segment drawn through them is a fair representation. It is this line segment, transformed back by the doubling rule, which yields the line segments in Figure 1. Therefore, a single line plus the doubling rule accounts for most of the variance in the data of Figure 1.

While a finding of either direct proportionality between $q$ and $B D$ or a step function like the one obtained would conform to the doubling rule, a related rule, multiplying or dividing by any integer, holds only for direct proportionality. The obtained step function requires that the multiplying rule be rejected.

Table 1 contains the stimulus durations for each stimulus set and the order in which the various base durations were measured. Table 2 presents the experimental results for each of the final three sessions at each base duration in terms of $q$ and $D_{c}$, the criterion, and also the values of $K$ and $\beta$. From these parameters and the equations given above, one can reconstruct the proportion of responses "long" for each stimulus duration. The values of $q$ in Figure 1 are the means of the six values of $q$ given in Table 2 for each base duration.

The criterion was set close to the base duration in every case, the differences between them ranging from -5 to $+8 \mathrm{msec}$ and averaging 0 over the 13 sets. Because of this, the obtained values of $q$ can be interpreted as the threshold $\Delta \mathrm{D}$ required for $87.5 \%$ correct responses.

Table 1

Stimulus Durations (in Milliseconds) for Each Base Duration and Order of Measurement

\begin{tabular}{|c|c|c|c|c|c|c|c|}
\hline $\begin{array}{c}\text { Base } \\
\text { Duration }\end{array}$ & $\begin{array}{c}\text { Order of } \\
\text { Measurement }\end{array}$ & $\mathbf{D}_{1}$ & $\mathrm{D}_{2}$ & $\mathrm{D}_{3}$ & $\mathrm{D}_{4}$ & $\mathrm{D}_{5}$ & $\mathrm{D}_{6}$ \\
\hline 100 & 11 & 85 & 90 & 110 & 115 & 95 & 105 \\
\hline 160 & 10 & 145 & 150 & 170 & 175 & 155 & 165 \\
\hline 200 & 9 & 165 & 185 & 215 & 235 & 190 & 210 \\
\hline 250 & 7 & 215 & 235 & 265 & 285 & 240 & 260 \\
\hline 350 & 8 & 315 & 335 & 365 & 385 & 340 & 360 \\
\hline 450 & 5 & 380 & 420 & 480 & 520 & 430 & 470 \\
\hline 570 & 2 & 500 & 540 & 600 & 640 & 550 & 590 \\
\hline 740 & 3 & 670 & 710 & 770 & 810 & 720 & 760 \\
\hline 800 & 13 & 730 & 770 & 830 & 870 & 760 & 840 \\
\hline 910 & 1 & 800 & 840 & 980 & 1020 & 880 & 940 \\
\hline 1080 & 4 & 970 & 1010 & 1150 & 1190 & 1050 & 1110 \\
\hline 1180 & 6 & 1070 & 1110 & 1250 & 1290 & 1150 & 1210 \\
\hline 1480 & 12 & 1345 & 1410 & 1550 & 1615 & 1450 & 1510 \\
\hline
\end{tabular}


Table 2

Experimental Results for Each of the Final Three Sessions at Each Base Duration

\begin{tabular}{|c|c|c|c|c|c|c|c|}
\hline \multirow{2}{*}{$\begin{array}{c}\text { Base } \\
\text { Duration }\end{array}$} & \multirow[b]{2}{*}{$\mathbf{K}$} & \multirow[b]{2}{*}{$\beta$} & \multirow[b]{2}{*}{ Session } & \multicolumn{2}{|c|}{$q$} & \multicolumn{2}{|c|}{$\mathrm{D}_{\mathrm{c}}$} \\
\hline & & & & $\mathrm{S}_{2} \mathrm{~S}_{3}$ & $\mathrm{~S}_{5} \mathrm{~S}_{6}$ & $\mathrm{~S}_{2} \mathrm{~S}_{3}$ & $S_{5} S_{6}$ \\
\hline 100 & .974 & .500 & $\begin{array}{l}18 \\
19 \\
20\end{array}$ & $\begin{array}{l}13.9 \\
15.5 \\
12.5\end{array}$ & $\begin{array}{l}13.3 \\
13.4 \\
13.3\end{array}$ & $\begin{array}{r}101 \\
97 \\
98\end{array}$ & $\begin{array}{l}101 \\
101 \\
100\end{array}$ \\
\hline 160 & .955 & .467 & $\begin{array}{l}18 \\
19 \\
20\end{array}$ & $\begin{array}{l}17.0 \\
11.0 \\
14.2\end{array}$ & $\begin{array}{l}18.7 \\
15.2 \\
17.8\end{array}$ & $\begin{array}{l}159 \\
161 \\
159\end{array}$ & $\begin{array}{l}163 \\
159 \\
161\end{array}$ \\
\hline 200 & .997 & .000 & $\begin{array}{l}18 \\
19 \\
20\end{array}$ & $\begin{array}{l}28.1 \\
25.2 \\
26.1\end{array}$ & $\begin{array}{l}21.6 \\
25.6 \\
21.7\end{array}$ & $\begin{array}{l}204 \\
205 \\
201\end{array}$ & $\begin{array}{l}203 \\
205 \\
202\end{array}$ \\
\hline 250 & .987 & .385 & $\begin{array}{l}18 \\
19 \\
20\end{array}$ & $\begin{array}{l}26.3 \\
26.8 \\
26.4\end{array}$ & $\begin{array}{l}21.0 \\
27.7 \\
28.8\end{array}$ & $\begin{array}{l}251 \\
252 \\
254\end{array}$ & $\begin{array}{l}253 \\
251 \\
253\end{array}$ \\
\hline 350 & .960 & .450 & $\begin{array}{l}18 \\
19 \\
20\end{array}$ & $\begin{array}{l}29.1 \\
30.5 \\
32.4\end{array}$ & $\begin{array}{l}31.3 \\
25.1 \\
37.7\end{array}$ & $\begin{array}{l}351 \\
348 \\
348\end{array}$ & $\begin{array}{l}349 \\
349 \\
349\end{array}$ \\
\hline 450 & .990 & .000 & $\begin{array}{l}18 \\
19 \\
20\end{array}$ & $\begin{array}{l}53.6 \\
43.3 \\
56.2\end{array}$ & $\begin{array}{l}44.9 \\
46.6 \\
37.7\end{array}$ & $\begin{array}{l}456 \\
445 \\
452\end{array}$ & $\begin{array}{l}460 \\
453 \\
450\end{array}$ \\
\hline 570 & .995 & .000 & $\begin{array}{l}18 \\
19 \\
20\end{array}$ & $\begin{array}{l}63.7 \\
61.4 \\
59.1\end{array}$ & $\begin{array}{l}52.9 \\
51.3 \\
69.8\end{array}$ & $\begin{array}{l}576 \\
568 \\
566\end{array}$ & $\begin{array}{l}558 \\
569 \\
563\end{array}$ \\
\hline 740 & .968 & .250 & $\begin{array}{l}18 \\
19 \\
20\end{array}$ & $\begin{array}{l}67.0 \\
65.5 \\
63.4\end{array}$ & $\begin{array}{l}50.7 \\
53.5 \\
62.3\end{array}$ & $\begin{array}{l}738 \\
738 \\
745\end{array}$ & $\begin{array}{l}749 \\
736 \\
744\end{array}$ \\
\hline 800 & .965 & .229 & $\begin{array}{l}18 \\
19 \\
20\end{array}$ & $\begin{array}{l}59.5 \\
67.7 \\
76.7\end{array}$ & $\begin{array}{l}67.4 \\
52.8 \\
60.7\end{array}$ & $\begin{array}{l}799 \\
814 \\
814\end{array}$ & $\begin{array}{l}804 \\
803 \\
794\end{array}$ \\
\hline 910 & .984 & .313 & $\begin{array}{l}18 \\
19 \\
20\end{array}$ & $\begin{array}{l}114.2 \\
108.5 \\
103.4\end{array}$ & $\begin{array}{r}90.9 \\
165.3 \\
95.7\end{array}$ & $\begin{array}{l}906 \\
903 \\
907\end{array}$ & $\begin{array}{l}914 \\
904 \\
915\end{array}$ \\
\hline 1080 & .958 & .738 & $\begin{array}{l}18 \\
19 \\
20\end{array}$ & $\begin{array}{r}94.4 \\
117.3 \\
107.7\end{array}$ & $\begin{array}{r}88.1 \\
138.9 \\
96.0\end{array}$ & $\begin{array}{l}1061 \\
1077 \\
1062\end{array}$ & $\begin{array}{l}1080 \\
1080 \\
1077\end{array}$ \\
\hline 1180 & .947 & .491 & $\begin{array}{l}18 \\
19 \\
20\end{array}$ & $\begin{array}{r}98.3 \\
129.2 \\
112.8\end{array}$ & $\begin{array}{l}118.3 \\
142.9 \\
105.4\end{array}$ & $\begin{array}{l}1185 \\
1179 \\
1170\end{array}$ & $\begin{array}{l}1183 \\
1196 \\
1188\end{array}$ \\
\hline 1480 & .917 & .470 & $\begin{array}{l}18 \\
19 \\
20\end{array}$ & $\begin{array}{l}161.5 \\
125.7 \\
132.3\end{array}$ & $\begin{array}{l}137.0 \\
115.8 \\
111.3\end{array}$ & $\begin{array}{l}1466 \\
1459 \\
1461\end{array}$ & $\begin{array}{l}1487 \\
1490 \\
1471\end{array}$ \\
\hline
\end{tabular}

Note-Quantum size and criterion are calculated twice for each session, once from the responses to $S_{2}$ and $S_{3}$ and once from $S_{5}$ and $S_{6}$ and are expressed in milliseconds.

The values of $q$ obtained from $S_{2}$ and $S_{3}$ differ little from those obtained from $S_{5}$ and $S_{6}$, the latter being $2 \mathrm{msec}$ smaller, on the average. This conforms to the expectation of the theory that $\mathrm{d}_{\mathrm{q}}$ is directly proportional to $\Delta \mathrm{D}$.

In order to compare these results with those of Getty (1975), the base duration function should be examined early in practice and without correcting the response proportions for failures to process via the factor $K$. This is shown in Figure 3, in which the mean uncorrected $q$ for Sessions $1-5$ is plotted as a function of base duration. It is a fairly convincing linear function which implies a direct proportionality between threshold and base duration (Weber's law). There is some evidence of a step at $800 \mathrm{msec}$, but not at the other locations, and one would be inclined to accept the linear fit. The intercept of the line passes within $1 \mathrm{msec}$ of 0 , and the slope of the line is .131 . This slope is equivalent to a ratio of SD to base duration of .053. Getty (1975) obtained Weber ratios of $.05-.06$ for each of his two subjects, thus there is remarkably good agreement between his results and the present results. ${ }^{3}$

The line of Figure 3 is reproduced as the dashed line in Figure 1. The two figures together indicate that the effect of specific practice is to cause the steps to unfold from the line, the practice effect being larger at the high end of each tread and minimal at the low end.

\section{Nature of the Practice Effect}

The q obtained in each session was transformed to the $q_{s o}$ level by the doubling rule, and the mean of 


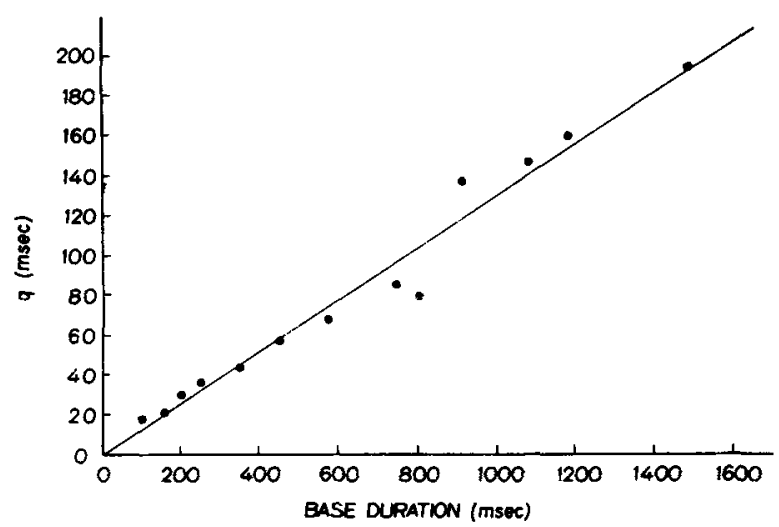

Figure 3. Mean q for Sessions 1-5 at each base duration without correction by $K$. The least squares line has a slope of .131 and an intercept of .6 msec. This means that the strict form of Weber's law is a good description of these data and that the standard deviation of the psychometric function divided by its mean is $\mathbf{. 0 5 3}$.

these was calculated over the 13 sets for each of the 20 sessions. The resulting practice curve is shown as Figure 4. Threshold decreases rapidly for the first halfdozen sessions and more slowly thereafter, with no indication that a lower limit is reached by Session 20 . The replacement of $S_{1}$ and $S_{2}$ by $S_{5}$ and $S_{6}$ following Session 15 resulted in a much more difficult task, the total number of errors within a session increasing markedly. Nonetheless, thresholds are only slightly elevated during Sessions 16 and 17, while the final three sessions fall close to the decreasing trend which exists from Session 6 onward. It is likely that this trend would have continued beyond Session 20 . If so, the steps in Figure 1 probably would become flatter.

The magnitude of the practice effect can be gauged by calculating the percentage reduction in $\mathrm{q}$ from Session 1 to Sessions 18-20. This gives slightly over $20 \%$ for the data of Figure 4. There is no indication that this magnitude decreased as the experiment progressed. For the six stimulus sets that were measured first, the mean percent reduction was 19 . For the last seven sets, it was 24 . Thus, there is a large practice component which is specific to a particular set, and, when, beginning a new set, prolonged practice is necessary with it regardless of the number of other sets the subject has practiced.

The procedure, which is intended to remove the effects upon the data of "failures to process," somewhat reduces the magnitude of the practice effect because $K$ also changes with practice, as depicted in Figure 5. The more that $K$ falls short of unity, the greater the reduction in $\mathrm{q}$ as a result of the correction. Since $K$ is smaller early in practice, $q$ is reduced more during the earlier sessions and progressively less as practice progresses. The result is to reduce the magnitude of the practice effect upon the apparent values of q. However, this tffect is not large, because $\mathrm{K}$ is relatively high throughout the experiment, the magnitude of the practice effect, as defined above, being $26 \%$ if the correction 2 r $\mathrm{K}$ is omitted compared to $22 \%$ if the correction is performed as it was for Figure 4.

A few errors a e maue to the monitoring stimuli $S_{1}$ and $S_{4}$ throughont this experiment: $K$ has not reached unity by $S_{i s s i o n} 15$. It has been demonstrated previously that the experimental subject in these experiments does yield a $\mathrm{K}$ of unity when practice is more extensive than the 20 sessions in the present experiment (Kristofferson, 1977). That theoretically ideal condition is not quite met in the present experiment.

Another point to be stressed about the practice effect is that it is not specific to the particular duration stimuli that are presented during practice. When $S_{5}$ and $S_{6}$, which have never been presented previously, are introduced in Session 16, discriminability between them yields the same $q$ as is obtained from $S_{2}$ and $S_{3}$. The value of $q$ may increase slightly during Sessions 16 and 17 , as discussed above, but it does so for both stimulus pairs. There is perfect transfer of practice to the new stimuli, as there should be according to the real-time cirterion theory (Kristofferson, 1977). All of the variance which produces errors in duration discrimination is variance in the criterion,

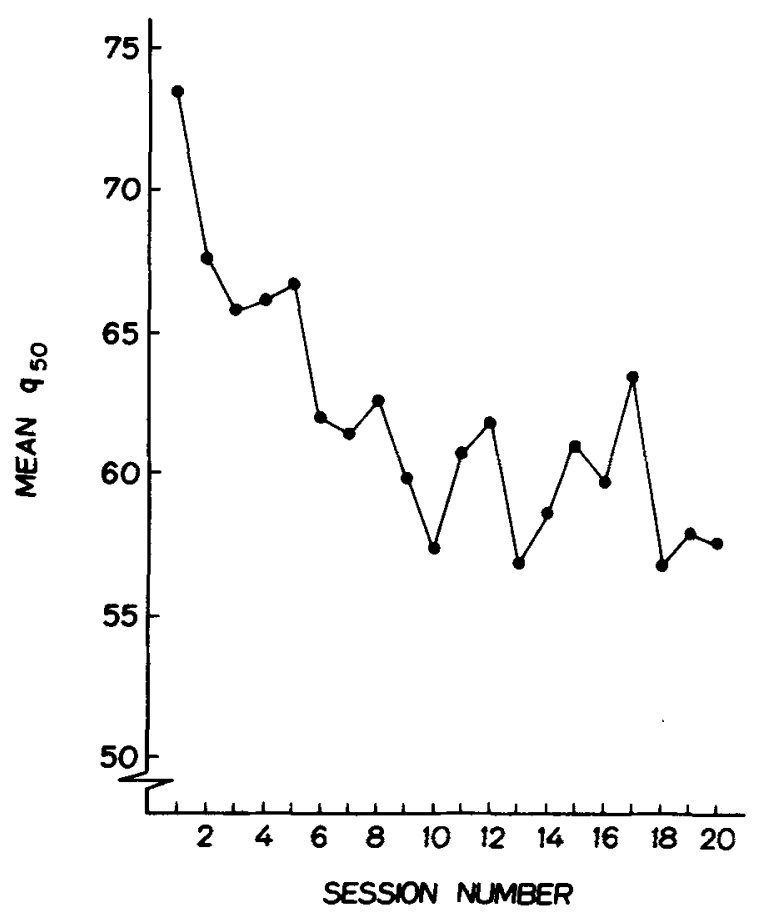

Figure 4. Mean qso over all 13 stimulus sets as a function of session number. For the first 15 sessions, $q$ is esiimated from $S_{2}$ and $S_{3}$ for each set. For each of the final 5 sessions, second estimate of $q$, from $S_{5}$ and $S_{6}$, is averaged in. 


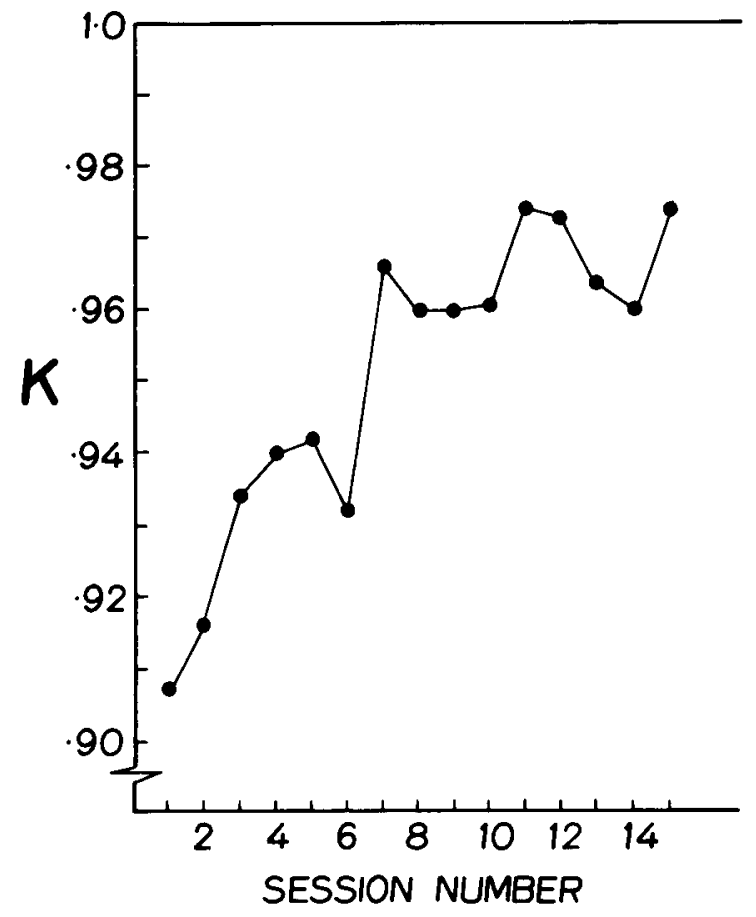

Figure 5. The probability of processing the stimulus, $K$, calculated from the monitoring stimuli $S_{1}$ and $S_{4}$ by Equation 1 as a function of session number. Average $K$ over all 13 stimulus sets.

and there is no variance in the timing of the sensory effects of the auditory pulses. Practice reduces the criterion variance.

A further reduction in $\mathrm{q}$, and a further flattening of the treads in the step function, might be found if more than 20 sessions of practice were given. That $\mathrm{q}$ would be further reduced is confirmed by comparing the earlier data (Kristofferson, 1977) with the function of Figure 1. The very extensive data in the earlier paper is for a single base duration of $1,100 \mathrm{msec}$, and the lower limiting value of $q$ was estimated to be $95.3 \mathrm{msec}$. This shown by the $\mathrm{X}$ in Figure 1. However, there were two other differences in procedure which might be significant to this comparison. In the earlier experiment, the subject had a single response button and he either responded or did not respond on each trial. Sometimes the response signaled the decision "long," and no response signaled "short" and sometimes the reverse. Perhaps more important is the fact that he responded as rapidly as possible; speeded responding was used. The response latencies were extremely short and of low variance, and the behavior might be characterized as "automatic." Whether discrimination is more acute under such conditions is as yet unknown, but it may well be so.

\section{GENERAL DISCUSSION}

When duration discrimination is measured as it has been measured here, the discrimination mechanism probably involves a real-time criterion (Kristofferson, 1977). On a trial, the onset of the duration stimulus initiates the internal timing of an interval of time which has a duration of $I \mathrm{msec}$. The end of $I$ is an event $C$, the criterion for that trial, and if $C$ occurs before the end of the stimulus, the stimulus is judged to be "long," while if the stimulus ends before C occurs, the judgment is "short." Duration discrimination is a temporal order judgment of $\mathrm{C}$ and stimulus termination.

Errors occur because I is variable from trial to trial, and in the limit the distribution of I, and hence the time of occurrence of $C$, is an isosceles triangle spanning $2 \mathrm{q} .{ }^{4}$ The threshold for duration is therefore determined by the amount by which I varies, and that, in turn, is determined solely by the size of the time quantum, the unit of temporal variance.

As base duration is increased, the internal interval I must also be increased so that the mean criterion, $D_{c}$, falls near the base duration. The quantal step function of Figure 1 therefore implies that values of I which average up to $200 \mathrm{msec}$ can be timed when $\mathrm{q}$ has a value of about $13 \mathrm{msec}$, those up to 400 when $\mathrm{q}$ is 25 , etc.

Theoretical difficulties appear when one tries to understand why larger values of the doubles set of $\mathrm{q}$ values are required for longer base durations (to time longer internal intervals). We seem to have to assume that $\mathrm{q}$ is involved in the timing of $\mathrm{I}$ because the variance of that timing and the range of base durations that can be serviced are both determined by the magnitude of $q$.

There is a simple, abstract logical mechanism which goes much of the way toward an understanding. It is an arbitrary choice, and it is to be hoped that a better mechanism can be found. It is to assume that the internal timing of an interval is accomplished by "counting" units of size q. The counting is done by some unknown neural mechanism, it certainly is not a conscious process and it probably does not involve the generation of a sequence of responses. There is an upper limit to the number of counts $\left(n_{c}\right)$ which is called U. For the data in Figure 1, $U$ is 16. As $I$ is made longer, $n_{c}$ must increase until it reaches 16 . A further increase in I requires that $q$ be increased by doubling so that $n_{c}$ can be halved to bring it back below 16 . This accounts for why the steps occur at 200,400 , and 800 and why the change in $q$ is what it is at those steps.

If it is assumed further that the counting is not error-free, and that the probability of an error in counting increases as $n_{c}$ increases, then the slope of the step treads will be a function of the slope of the counting error function. The observed unfolding of the steps with practice can then be attributed to a progressive reduction in counting errors.

At any quantum level, intervals from $1 \mathrm{q}$ to $16 \mathrm{q}$ can be timed. For example $\mathrm{q}_{100}$ can be used to time all I between 100 and 1,600 msec. If an I of $300 \mathrm{msec}$ 
is required; it might be timed by $q_{100}, q_{s 0}$, or $q_{25}$. The lowest possible level is used because it minimizes errors. Similarly, counts greater than 16 may be possible, but counting errors may become so large that discrimination errors are minimized by moving up to the next $q$ level instead.

There is an important aspect of the data which is not accounted for by the simple quantum counter. It is that the mean criterion, $D_{c}$, can be placed very close to the midpoint of the stimulus set regardless of the position of the midpoint. $D_{c}$ is continuously variable, while values of I generated by $n_{c} \times q$ are discrete, only multiples of $q$ being possible. To account for this, it is necessary to make yet another assumption, such as $\overline{\mathbf{I}}=\mathrm{n}_{\mathrm{c}} \times \mathrm{q}+\mathrm{a}$, where $\mathrm{a}$ is a continuously adjustable time interval which is deterministic (since the variance of $I$ is determined only by $q$ ). Such an interval, a, might be available in the afferent latencies of the auditory pulses and it might be deterministic (see Kristofferson, 1976, 1977).

This is enough to demonstrate that the quantal counting hypothesis is one starting point for theory and also that it places a great burden upon imagination at the present time.

In a recent study of response-stimulus synchronization (Kristofferson, 1976), it was shown that the interval between a stimulus and a response can be experimentally controlled so that the response is delayed for any desired time. For response delays greater than reaction time, the mean delay can be increased without increasing the variance of the delays: the added delays are deterministic. This is true of added delays up to a limit of $\mathbf{4 0 0} \mathrm{msec}$. Within this range of deterministic delays, the distribution of response latencies resembles an isosceles triangle with a base of $50 \mathrm{msec}$. In other words, $\overline{\mathbf{I}}$ can be generated in values up to $400 \mathrm{msec}$ when $q$ is 25 , just as in the present experiment. Turning this around, it can be seen that if additional experiments, which are under way, do find flat treads on the step function, it will be possible to conclude that, when operating on the $\mathrm{q}_{100}$ level, deterministic added delays are possible which may be as long as $1,600 \mathrm{msec}$.

The doubling rule is the answer to the question raised in the introduction. The time quantum can be thought of as associated with a periodicity which is not fixed but instead is capable of doubling and halving. As a result, $q$ is a set of values close to $13,25,50$, and $100 \mathrm{msec}$. Whether another doubling occurs to a $q_{200}$ level at $1,600 \mathrm{msec}$, we do not know yet. $^{3}$

\section{REFERENCES}

Allan, L. G. The perception of time. Perception \& Psychophysics, 1979, 26, 340-354.
Allan, L. G., \& Kristofferson, A. B. Judgments about the duration of brief stimuli. Perception \& Psychophysics, 1974, $15,434-440$.

Allan, L. G., Kristofferson, A. B., \& Wiens, E. W. Duration discrimination of brief light flashes. Perception \& Psychophysics, 1971, 9, 327-334.

Divenyi, P. L., \& Danner, W. F. Discrimination of time intervals marked by brief acoustic pulses of various intensities and spectra. Perception \& Psychophysics, 1977, 21, 125-142.

GETTY, D. J. Discrimination of short temporal intervals: A comparison of two models. Perception \& Psychophysics, 1975, 18, 1-8.

Kristofferson, A. B. Attention and psychophysical time. Acta Psychologica, 1967, 27, 93-100.

KRISTOFFERSON, A. B. Low-variance stimulus-response latencies: Deterministic internal delays? Perception \& Psychophysics, 1976, 20, 89-100.

Kristoffe rSON, A. B. A real-time criterion theory of duration discrimination. Perception \& Psychophysics, 1977, 21, 105-117.

Kristofferson, A. B., \& Allan, L. G. Successiveness and duration discrimination. In S. Kornblum (Ed.), Attention and performance IV. New York: Academic Press, 1973.

\section{NOTES}

1. In Kristofferson $(1976,1977)$, the frequency of the tonal markers was incorrectly reported to have been $1,000 \mathrm{~Hz}$. It was $2,000 \mathrm{~Hz}$ in those experiments also.

2. In Kristofferson (1977), 30 sessions were found to be necessary to reach a stable, low level.

3. In a recent paper, Divenyi and Danner (1977) report data which also support Weber's law. They give a value of .063 for the average Weber ratio, which agrees well with those discussed here, and they comment that such a value may "approximate the ultimate limits of what a human observer can do." They also summarize three other studies, which all report larger Weber ratios. But after 17 sessions of specific practice, the data in Table 2 and Figure 1 show that the Weber ratio reaches a low of .033 just prior to the jump to a new $q$ level as base duration is increased.

Divenyi and Danner's subjects were very highly practiced, but the practice was probably not specific to a particular base duration. One cannot be certain from their descriptions of their procedure, but they appear to have changed base duration frequently, probably even within each session. Also, they used only three base durations, 25,80 , and $320 \mathrm{msec}$.

4. The parameter $q$ is used throughout this paper as an estimate of the variability of the criterion distribution. It is possible that early in practice, some distribution such as the normal distribution is a better descriptor of the criterion distribution than is the triangular distribution upon which $q$ is based. The important point is that when $q$ is shown to change with practice, it is not known whether that change is in the value of the time quantum or in some variance source elsewhere in the system. It might be either or both. I do not wish to conclude that the size of the time quantum changes with practice.

5. While the real-time criterion theory of duration discrimination (Kristofferson, 1977) has been used in the interpretation of the present results, the phenomenon of quantal doubling is not a deduction from that theory and the experiment reported here is not a test of that theory.

(Received for publication September 10, 1979; revision accepted February 7,1980 .) 